Electronic version of an article published as [European Journal of Operational Research, 2007, Vol. 117, No. 3, p. 1495-1506] [DOI:

http://dx.doi.org/10.1016/j.ejor.2005.04.017] (c [copyright Elsevier] 


\title{
Using a MILP model to establish a framework for an annualised hours agreement $^{1}$
}

\author{
Albert Corominas; Amaia Lusa² ; Rafael Pastor \\ Research Institute (IOC) / Engineering school (ETSEIB) \\ Universitat Politècnica de Catalunya (UPC); Barcelona; Spain \\ \{albert.corominas/amaia.lusa/rafael.pastor\}@upc.es
}

\begin{abstract}
Production flexibility is essential for industrial companies that have to deal with seasonal demand. Human resources are one of the main sources of flexibility. Annualising working hours (i.e., the possibility of irregularly distributing the total number of working hours over the course of a year) is a tool that provides flexibility to organizations; it enables a firm to adapt production capacity to fluctuations in demand. However, it can imply a worsening of the staff's working conditions. To take the human aspect into account, the planning and scheduling of working time should comply with constraints derived from the law or from a collective bargaining agreement. Furthermore, new and more difficult working-time planning and scheduling problems are arising. This paper proposes a mixed-integer linear program model to solve the problem of planning the production and the working hours of a human team that operates in a multi-product process. Solving the model for different settings provides the essential quantitative information to negotiate the best conditions of the annualised hours system (the elements to establish the trade-off between weekly flexibility and economic or working-time reduction compensation can be obtained). The results achieved in a computational experiment were very satisfactory.
\end{abstract}

Keywords: human resources, manpower planning, annualised hours, integer programming.

\footnotetext{
${ }^{1}$ Supported by DPI2001-2176 project

${ }^{2}$ Corresponding author: Amaia Lusa, Research Institute IOC, Av. Diagonal 647 (edif. ETSEIB), p.11, 08028 Barcelona, Spain; Tlf. + 343401 17 05; Fax. + 3434016605 ; e-mail: amaia.lusa@upc.es
} 


\section{Introduction}

At the present time, production flexibility is essential for industries that have to deal with seasonal demand. One of the main sources of flexibility is flexibility in human resources. Annualising working hours $(\mathrm{AH})$ consists in hiring workers for a certain number of hours per year and distributing those hours irregularly over the course of the year to face demand fluctuations. It allows a better use of potential capacity: one can better adapt capacity to demand throughout the year and, in this way, reduce inventory levels and lost demand (and their associated costs).

There are other tools that can provide flexibility within organizations: overtime, part-time workers and temporary contracts are the most common. Oke (2000) enumerates different actions aimed at providing flexibility in the use of human resources. This author indicates that, according to his work, approximately $40 \%$ of the companies consider AH to be one of the most desirable options, mainly because of its low cost; however, it is still an uncommon option (around 10\%).

The major advantage of annualising working hours is the reduced economic cost in comparison to other options. By using AH, costs due to a lack of capacity can be diminished and, in some cases, eliminated. Vila and Astorino (2001) give an example of a real AH scenario: an agricultural machinery manufacturer that introduced $\mathrm{AH}$ was able to reduce overtime and the use of temporary workers by $94 \%$ and $53 \%$ respectively. A reduction in the use of temporary workers can also lead to an improvement in productivity and in the quality of the product or service. Furthermore, the service level can be improved, since demand can be covered on time.

However, AH often implies a worsening of the staff's working conditions (e.g., an irregular schedule may affect a worker's private life) and the need to solve a complicated problem in planning working time.

To minimise the negative consequences for workers, the annualisation of working time has to be negotiated and may be accompanied by some sort of compensation or incentive: a reduction in annual working time, additional holidays or financial compensation. At the same time, constraints derived from the law or from a collective bargaining agreement must be respected to avoid excessively overburdening workers during long, high-demand periods. For instance, in France, a law called the "Aubry II Law" or the "35 Hours Law" (see MES, 2003) established a general 
reduction in the total number of annual working hours, without a reduction in wages. This law permits an irregular distribution of hours throughout the year and establishes the following rules: (i) the weekly number of working hours must fall within an interval defined by a lower and an upper bound; (ii) the total annual working hours is upper bounded; and (iii) the average of the weekly working hours, for any set of twelve consecutive weeks, is upper bounded.

Corominas and Pastor (2000), point out the following paradox: by reducing the average weekly working hours from 40 to 35 and accompanying this reduction with an AH system, a company could meet the same demand, reduce its workforce and the cost due to overtime and temporary workers. Of course, this is due to the flexibility permitted by annualised hours, which allows the company to plan working time in a more efficient way.

To negotiate financial compensation or a reduction in working time in exchange for flexibility, the company and its workers must ascertain by how much profit could be increased (or costs decreased) based on the level of flexibility (which can be determined by the lower and upper bounds of the weekly working hours) and the reduction in working time.

Planning production and working time by considering different annualised hours scenarios (for example, different numbers of annual working hours and different levels of weekly flexibility) provides the company and its workers with quantitative information, which is essential for a collective bargaining process. By testing several situations, the company could evaluate the tradeoff between the weekly flexibility accepted by workers and the reduction in annual working time or the financial compensation offered by the company in exchange for the worsening of working conditions. In Section 4, a specific case is explained to show how profit is increased, due to weekly flexibility, even when annual working time is reduced.

The practice of annualising hours is a source of flexibility of ever greater importance. The number of firms that are signing AH contracts is rising. However, and in spite of its growing importance, the manpower planning and scheduling problems raised by AH have not been widely studied up to the present.

Chan and Weil (2002) propose a method based on the use of different models within the Constraint Satisfaction framework to solve the problem of planning and scheduling in one step (they solve the 
problem using a very small number of workers) but, as happens generally with this sort of problem, a hierarchical approach is needed to solve it when the number of workers is large.

In Corominas and Pastor (2000), Corominas et al. (2002b) and Campbell and Diaby (2002), a three-phase method is proposed, in which planning, scheduling and task-assignment or allocation problems are successively solved. Actually, this method can be considered as an application of the hierarchic planning approach that has been established for manufacturing activities since many years (Hax and Meal, 1973).

This paper deals with the first phase: to solve the problem of planning working time and, since a manufacturing company is considered, planning also production. As far as aggregated planning consists in specifying a combination of production rate, workforce level and inventory, with an horizon from about a year, in order to meet demand and optimising costs or the level of service, the first phase of the proposed method is just a case of aggregate planning, with the distinctive feature of determining an irregular distribution of working hours throughout the year fulfilling specific rules derived from law or collective bargain agreement.

Many planning models are been proposed since the pioneer HMMS (Holth, Modigliani, Muth and Simon, 1960) and some of them consider tools to adjust production capacity. Of course determination of workforce level is an aspect included in most of these models but, essentially, the only options they include are overtime and the firing \& hiring scheme, considering its costs but assuming complete freedom in hiring and firing (see, for instance, Johnson and Montgomery, 1974; Hax and Candea, 1984). At the best of our knowledge, however, models including annualised hours are not been published and, in fact, Hung (1997) is the first author who suggests that aggregate planning should explore the possibilities of annualised hours. The annualisation of working hours is a subject that remains largely unexplored. Several papers (for example, Clutterbuck 1982, Curran 1992, Lynch 1995, MacMeeking 1995 and Mazur 1995) discuss AH, but only from a qualitative point of view.

Hung (1999b) states that "A problem that employers face when planning for AH is the scheduling of workers over the year. To our knowledge, there is no literature on this issue”. Grabot and Letouzey (2000) reiterate that the concept of annualised hours "is surprisingly absent from the literature on scheduling, with the exception of the recent studies of Hung on the subject”. Finally, 
in a review of the state of the art in workforce planning studies for industry, Azmat and Widmer (2004) only include the works of Hung.

Hung (1999a, 1999b) proposes algorithms for weekly scheduling in the context of AH, but he does not consider, for example, constraints similar to the ones established by the French law cited above. Based on Hung, Azmat and Widmer (2004) propose a three-step heuristic approach to solve planning and scheduling for AH. Corominas and Pastor (2000) propose the use of MILP to solve the problem of planning annualised working hours, but they note that there are many different types of problems, each of which requires a specific modelling and solution approach.

In Corominas et al. (2002a), the characteristics of the planning problem are discussed and a classification scheme is proposed, which gives rise to thousands of different cases. Several of the types of problems (the most common) have already been solved. Corominas et al. (2002b) use MILP to solve the problems of planning staff working hours using an annual horizon and two hierarchical categories of workers, minimising the cost due to overtime and temporary workers; and regularising, for each worker, the distribution of working time over the course of the year. Corominas et al. (2002c and 2004) deal with the problem of planning annual working hours in which the weekly number of working hours for any worker must fall within a previously agreed interval. In all such cases, and in spite of the large size of the models, MILP has been shown to be an efficient tool for solving these kinds of problems.

By solving working time and production planning in annualised hours scenarios, one can see how capacity is adapted to demand. Also, if an AH system is compared to a traditional system (regular working hours), one can see how the costs due to overtime, temporary workers, subcontracting, lost demand and, in some cases, inventory are diminished.

Subsequent sections of this paper show how a MILP model could be used to establish a framework for collective bargaining in order to introduce annualised hours in a company. They are organised as follows: Section 2 introduces the problem; Section 3 describes the planning model; Section 4 describes the computational experiment and shows the main results of a specific case; and in Section 5 the authors put forward their conclusions. 


\section{Production planning under annualised hours}

The planning problem consists in determining the weekly production and the weekly number of working hours for a human team involved in a multi-product industrial process and for each nonholiday week of the planning horizon (a year, for instance), with the objective of optimising a utility function (in this case, the profit). It is assumed that all team members must carry out the same working hours (the process requires the intervention of all team members); that there are different products to plan and their forecasted demand is known; and that during holiday periods, which are previously agreed, there is no production but the demand still exists.

When there is insufficient inventory to respond to demand, the company can defer it (within the same year) for a finite time; at such times, there may be lost demand.

The conditions to be fulfilled by the solution may come from a legal resolution, such as the French 35 Hours Law, or from a collective bargaining agreement between management and workers. Due to the impossibility of establishing an exhaustive list of conditions a priori, the most common conditions are considered to build a basic model for the problem (some of these have been found in collective bargaining agreements and some have been determined through real cases). To adapt this model to a specific case, constraints can be added or deleted.

As an example, the French law requires that the weekly number of working hours must fall within an interval defined by a lower and an upper bound; that the total annual working hours be upper bounded; and that the average of the weekly working hours, for any set of twelve consecutive weeks, be upper bounded (it is assumed that this condition applies only to sets of twelve consecutive non-holiday weeks).

To consider the workers' working conditions, the collective agreement may also state that a working week can be considered "weak" or "strong”, depending on the number of working hours (for example, no more than 30 hours/week and more than 44 hours/week respectively). The annual number of "weak" working weeks is lower bounded (for example, 10 weeks); the annual number of “strong” working weeks is upper bounded (for example, 15 weeks).

The characteristics of the problem are summarised as follows: 
- There are different products and their forecasted demand is known.

_ All team members must perform the same working hours.

- The annual number of ordinary working hours is fixed. Additional hours are considered overtime.

- Annual overtime is upper bounded.

- The weekly number of working hours is lower and upper bounded.

- The average working hours for a group of $L$ non-holiday consecutive weeks cannot be greater than $h_{L}$ hours/week.

- The annual number of "weak" working weeks is lower bounded (a week is "weak" if the number of working hours is no greater than $h_{B}$ hours).

- The annual number of "strong" working weeks is upper bounded (a week is "strong" if the number of working hours is greater than $h_{A}$ hours).

- The team of workers has two consecutive holiday weeks in winter and four consecutive holiday weeks in summer (previously agreed).

- The company can defer the demand (the delay is upper bounded, so there may be lost demand).

- Profit is to be maximised.

These conditions can be modelled as linear constraints.

\section{Model}

We make use of the following notation.

\section{Data:}

number of weeks of the planning horizon (usually 52).

set of available weeks of the workers' team (the weeks of the planning horizon excluding holiday weeks). 
$s t_{q 0}$

$H$

$M Y$

$h m_{t}, h M_{t} \quad$ lower and upper bound for the weekly number of working hours.

$L, h_{L} \quad$ the average of working hours in any group of $L$ consecutive working weeks cannot be greater than $h_{L}$ (in that case, $L=12$ and $h_{L}=44$ hours).

$X 0_{t}$

$A, h_{A}$

$B, h_{B}$

$d_{q t}$

td

$T P_{q}$

$\rho_{q t}$

$C E$

$\mathrm{CST}_{q}$

$C R_{q}$

$I_{q t}$

number of products.

inventory of product $q$ at the beginning of the planning horizon $(q=1, \ldots, Q)$.

annual number of ordinary working hours.

maximum annual overtime.

number of working hours in week $\mathrm{t}(\mathrm{t}=2-L, \ldots, 0)$; $\mathrm{t}=0$ corresponds to week 52 (last week) of previous year, $\mathrm{t}=-1$ corresponds to week 51 of previous year, and so on. This information allows to take into account initial conditions (working hours corresponding to the last $L-1$ weeks of the previous year) when modeling constraint affecting the average of working hours in any group of $L$ consecutive working weeks.

$A$ is the maximum number of "strong" weeks (i.e., weeks with a number of working hours greater than $\left.h_{A}\right) ; h m_{t} \leq h_{A} \leq h M_{t}$.

$B$ is the minimum number of "weak" weeks (i.e., weeks with a number of working hours not greater than $\left.h_{B}\right) ; h m_{t} \leq h_{B} \leq h M_{t}$.

forecasted demand for products of type $q$ in week $t(\mathrm{q}=1, \ldots ., \mathrm{t}=1, \ldots, T)$.

maximum number of weeks that a demand can be deferred.

average time (in hours) needed to prepare the process to produce product $q$ $(\mathrm{q}=1, \ldots, Q)$.

productivity (in units/hour) for product $q$ in week $t(\mathrm{q}=1, \ldots, \mathrm{Q}, \mathrm{t}=1, \ldots, T)$; in some weeks productivity could be smaller than usual.

cost of overtime.

weekly inventory holding cost of one unit of product $q(q=1, \ldots, Q)$.

cost of one unit of lost demand of product $q(\mathrm{q}=1, \ldots, Q)$.

income of one unit of product $q(\mathrm{q}=1, \ldots, Q)$ served with a delay of $t$ weeks $(\mathrm{t}=0, \ldots, t d)$; the costs of deferring are supposed to be included in that parameter and, this way, that $I_{q, t-1}>I_{q, t}>I_{q, t+1}$. 


\section{Variables:}

$x_{t} \quad$ non-negative real variable that indicates the number of working hours in week $t, \forall t$ $\in S$.

$y \quad$ non-negative real variable that indicates the annual overtime.

$a_{t} \in\{0,1\} \quad$ if the number of working hours in week $t$ is greater than $h_{A}$ (the week is "strong”), then these variables take value $1, \forall t \in S$.

$b_{t} \in\{0,1\} \quad$ if the number of working hours in week $t$ is greater than $h_{B}$ (the week is not “weak”), then these variables take value $0, \forall t \in S$.

$p_{q t} \quad$ non-negative real variable that indicates the quantity of product $q$ produced in week $t(\mathrm{q}=1, \ldots, Q ; \forall t \in S)$.

$e_{q t} \in\{0,1\} \quad$ indicates if product $q$ is produced in week $t(\mathrm{q}=1, \ldots, Q ; \forall t \in S)$.

$s t_{q t} \quad$ non-negative real variable that indicates the inventory of product $q$ at the end of week $t(\mathrm{q}=1, \ldots, Q ; \mathrm{t}=1, \ldots, T)$.

$v_{q s t} \quad$ non-negative real variable that indicates the quantity of the demand of product $q$ of week $s$, that is served in week $t(\mathrm{q}=1, \ldots, Q ; s=1, \ldots, \mathrm{T} ; \mathrm{t}=s, \ldots, \min (s+t d, T))$.

$r_{q t} \quad$ non-negative real variable that indicates the quantity of demand of product $q$ in the week $t$ not served and lost $(\mathrm{q}=1, . ., Q ; \mathrm{t}=1, \ldots, \mathrm{T})$.

\section{Model:}

$$
\begin{array}{lc}
{[M A X] Z=\sum_{q=1}^{Q} \sum_{s=1}^{T} \sum_{t=s}^{\min (s+t d, T)} I_{q, t-s} \cdot v_{q s t}-C E \cdot y-\sum_{q=1}^{Q} \sum_{t=1}^{T}\left(C S T_{q} \cdot s t_{q t}+C R_{q} \cdot r_{q t}\right)} \\
\sum_{t \in S} X_{t}=H+y & \\
\sum_{t=s}^{\min (s+t d, T)} v_{q s t}+r_{q s}=d_{q s} & q=1, \ldots, Q ; s=1, \ldots, T \\
p_{q t}+s t_{q, t-1}=\sum_{s=\max (t-t d, 1)}^{t} v_{q s t}+s t_{q t} & q=1, \ldots, Q ; \forall t \in S
\end{array}
$$




$$
\begin{array}{lc}
s t_{q, t-1}=\sum_{s=\max (t-t d, 1)}^{t} v_{q s t}+s t_{q t} & q=1, \ldots, Q ; \forall t \notin S \\
\sum_{q=1}^{Q}\left(\frac{p_{q t}}{\rho_{q t}}+T P_{q} \cdot e_{q t}\right) \leq x_{t} & \forall t \in S \\
p_{q t} \leq e_{q t} \cdot \rho_{q t} \cdot\left(h M_{t}-T P_{q}\right) & q=1, \ldots, Q ; \forall t \in S \\
\sum_{t=j-L+1}^{0} X 0_{t}+\sum_{\forall t \in([1, j] \cap S)} x_{t} \leq h_{L} \cdot L & j=1, \ldots, L-1 \mid\left[[1, j] \in S \wedge\left(X 0_{t}>0, \forall t \in[j-L+1,0]\right)\right] \\
\sum_{t=j-L+1}^{j} x_{t} \leq h_{L} \cdot L & \forall t \in S \\
x_{t} \leq h_{A}+\left(h M_{t}-h_{A}\right) \cdot a_{t} & \\
\sum_{t \in S} a_{t} \leq A & \\
x_{t} \leq h M_{t}+\left(h_{B}-h M_{t}\right) \cdot b_{t} & \\
\sum_{t \in S} b_{t} \geq B & \\
y \leq M Y & \\
x_{t}, y, p_{q t}, s t_{q t}, v_{q s t}, r_{q t} \geq 0 & \\
a_{t}, b_{t}, e_{q t} \in\{0,1\} &
\end{array}
$$

The objective function to maximise, (1), is the profit (income minus overtime, inventory and lost demand costs). (2) expresses the annual balance of working hours. (3) expresses the served and required demand balance. (4) and (5) express the production, inventory and served demand balance (note that Equation (5) is used during holiday weeks, when there is no production but demand still exists). (6) imposes an upper bound production, depending on weekly working hours. It considers the average time (in hours) needed to prepare the process to produce product $q$. (7) imposes an upper bound production for each product (considering the preparation process times) and forces the binary variable $e_{q t}$ to take value 1 if product $q$ is produced in week $t$. (8) and (9) impose the upper bound to the average of weekly working hours for any subset of $L$ consecutive non-holiday weeks. 
Note that initial conditions (working weeks belonging to previous year) are considered in (8). If these working weeks were not took into account (i.e., equation (8) not included), the law it might not be respected in weeks 1 to $L-1$. Equation (10), if the team works a number of hours greater than $h_{A}$ in week $t$ (i.e. if it is a "strong” week), forces the binary variable, $a_{t}$, to take value 1 . Equation (11) imposes an upper bound for the number of weeks in which the binary variable, $a_{t}$, can take value 1. Thus, (10) and (11) impose the upper bound for "strong" weeks. Equation (12), if the team works a number of hours greater than $h_{B}$ in week $t$ (i.e. if it is not a "weak" week), forces the binary variable, $b_{t}$, to take value 0 . Equation (13) imposes a lower bound for the number of weeks in which the binary variable $b_{t}$ can take value 1 . Thus, (12) and (13) impose the lower bound for "weak" weeks. (14) imposes the upper bound for annual overtime. (15) imposes the lower bound for weekly working hours (note that the upper bound is included in (10) and (12)). and finally, (16) and (17) express the non-negative and binary character of the variables.

\section{Computational experiment}

A computational experiment was performed to evaluate the operativeness of the MILP model (short solving times) and the main results of annualising working time (compare the results obtained for different situations). Overall, these results can be considered to be very satisfactory.

The basic data used for the experiment are as follows:

- $\quad T=52$ (considering 46 working weeks and 6 holiday weeks).

- In all instances, the annual number of holiday weeks is constrained to be equal to six, distributed into two non-interrupted parts, one two and the other four weeks long. The temporary location of holidays has been fixed at random (the two weeks of the first period, in winter, and the four weeks of the second period, in summer). This way of generating holiday weeks might be not very realistic, but it does not make solving the models any easier.

- $\quad Q=1$ and $Q=10$ number of products.

$-T P_{q}=0$. 
- $\sum_{q=1}^{Q} s t_{q 0}=30$ (inventory at the beginning of the planning horizon). When $q>1$ the inventory is equally distributed among products.

$-X O_{t}=0(\mathrm{t}=2-L, \ldots, 0)$.

- To evaluate different situations under which one would establish a negotiation framework, three levels of $H$ were considered, depending on the reduction in working time as a compensation for the worsening of working conditions: 1,840 hours (corresponding to an average of 40 hours/week); 1,748 hours (corresponding to an average of 38 hours/week); and 1,610 hours (corresponding to an average of 35 hours/week).

- Also, four different lower and upper bounds were considered for weekly working hours, depending on the weekly flexibility accepted by the workers: [40, 40] (which corresponds to a non-AH situation without overtime and which is only considered when $H=1,840$ hours/year); [40,50] (which might correspond to a non-AH situation with weekly overtime and which is only considered when $H=1,840$ hours/year); [30, 45]; and [25, 50].

- $\quad L=12$ weeks; $h_{L}=44$ hours/week (when possible; not for $[40,40]$ )

- $A=15$ weeks; $h_{A}=44$ hours/week (when possible; not for [40, 40])

- $B=10$ weeks; $h_{B}=30$ hours/week (when possible; not for $[40,40]$ or $[40,50]$ ).

- There are three different demand patterns throughout the year: Demand Type 1 corresponds to a non-seasonal capacity pattern (the required capacity is the same for every week in the planning horizon); Demand Type 2 corresponds to a seasonal pattern with one peak; and Demand Type 3 corresponds to a seasonal pattern with two peaks. In each case, total demand is approximately equal to total capacity. Figures 1, 2 and 3 show the shapes of these patterns. Furthermore, the peaks can be more or less pronounced; three levels were considered (small peaks, medium peaks and high peaks). 




Figure 1. Type of demand 1 (no seasonality)

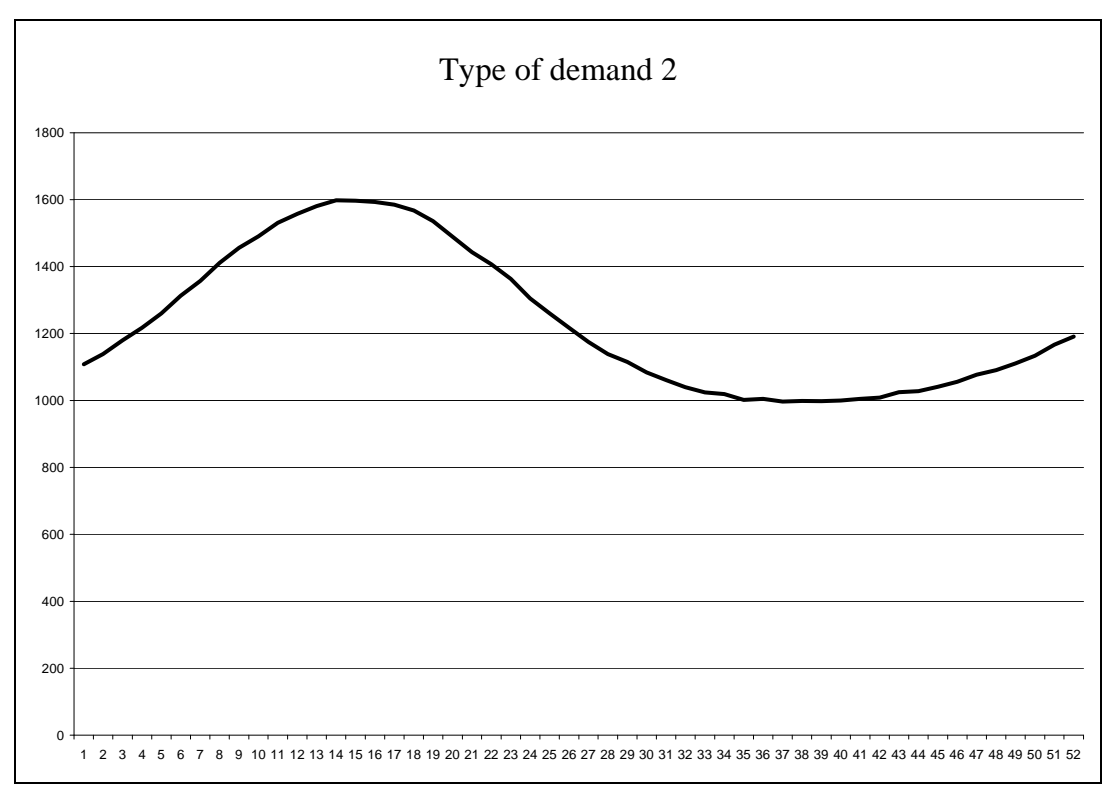

Figure 2. Type of demand 2 (one peak) 


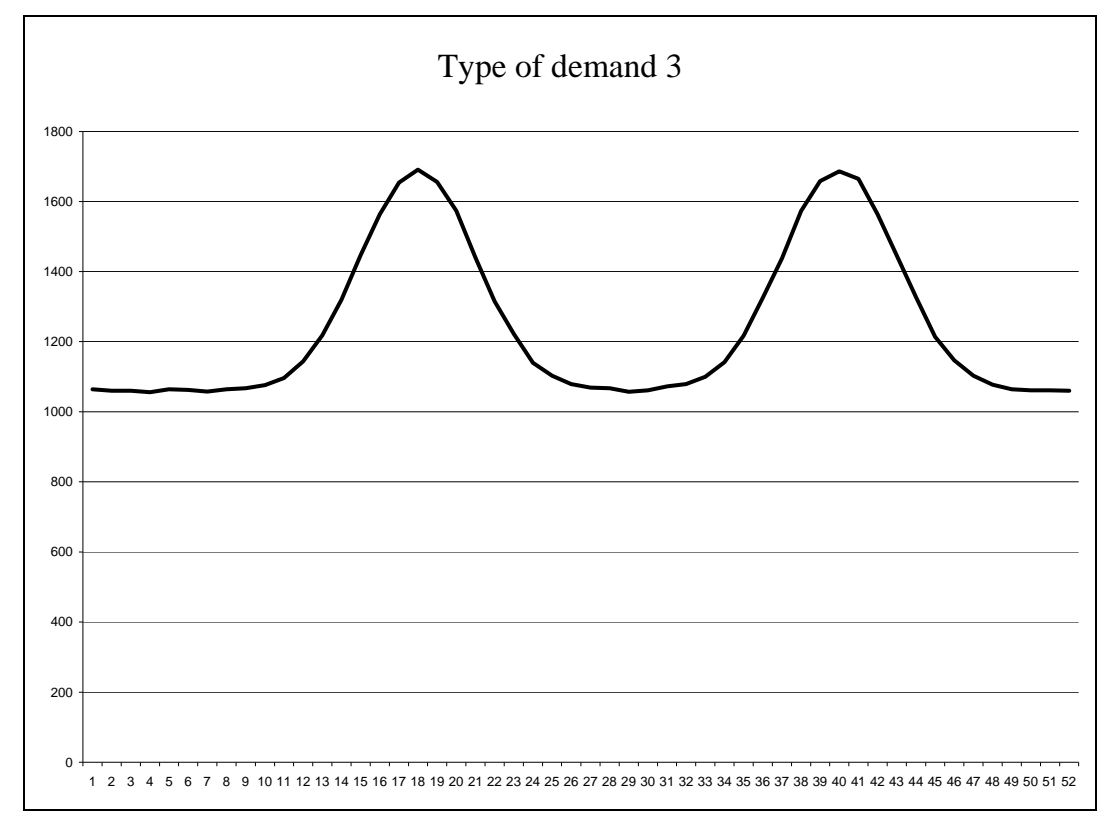

Figure 3. Type of demand 3 (two peaks)

The operativeness of the model was tested by using the ILOG CPLEX 8.1 optimiser and a PC Pentium IV at $1.80 \mathrm{GHz}$ with $512 \mathrm{Mb}$ of RAM to solve 336 instances (for $Q=10$ products), which were obtained as follows:

- 3 types of demand,

- 3 levels of peak demands (only for the second and third types of demand),

- 3 levels of inventory holding costs (low, medium and high),

- 2 levels for the maximum delay to serve the demand (low and high),

- 8 combinations for annual hours and the lower and upper bounds for weekly working hours.

Optimally solving the model is not difficult; in most cases, the solution times were less than five seconds and, in the worst case, the computing time was less than 11 minutes (the longest times correspond to instances of Demand Type 1 and maximum weekly flexibility). Thus, the results can be considered to be very satisfactory; the company could solve several scenarios in a short time and then establish the framework for collective bargaining.

Solving the model for different levels of flexibility and working time reduction provides the company and the workers with the information that they require before agreeing to the conditions of the annualised hours system. Table 1 shows the results of a specific case, where $Q=1$ product 
( $K$ is the profit obtained in a situation without flexibility and without a reduction in working time). The company can see how the profit increases when flexibility is high, even when reducing working time or offering financial compensation for the worsening of their working conditions.

\begin{tabular}{|c|c|c|c|c|c|}
\cline { 3 - 6 } \multicolumn{1}{c|}{} & \multicolumn{5}{c|}{$[h m, h M]$ (hours/week) } \\
\cline { 2 - 7 } \multicolumn{1}{c|}{} & $\mathrm{z}^{*}$ (profit) & {$[40,40]$} & {$[40,50]$} & {$[30,45]$} & {$[25,50]$} \\
\hline \multirow{3}{*}{\begin{tabular}{c} 
(hours/year) \\
\cline { 2 - 6 }
\end{tabular}} & 1,840 & $\mathrm{~K}$ & $1.29 \cdot \mathrm{K}$ & $1.37 \cdot \mathrm{K}$ & $1.42 \cdot \mathrm{K}$ \\
\cline { 2 - 6 } & 1,748 & & & $1.36 \cdot \mathrm{K}$ & $1.42 \cdot \mathrm{K}$ \\
\cline { 2 - 6 } & 1,610 & & & $1.20 \cdot \mathrm{K}$ & $1.34 \cdot \mathrm{K}$ \\
\hline
\end{tabular}

Table 1. Example of decisions (weekly flexibility and annual hours) that result in an increase in the profit

Two methods to increase the profit by implementing annualising hours might be as follows: (1) by increasing weekly flexibility, and reducing working time as compensation for the workers; or (2), by increasing flexibility, and not reducing working time but instead offering financial compensation to the workers. The company and the workers can agree to satisfactory conditions for both.

The great increase in profit is due to the reduction in inventory levels and in lost and deferred demand. Figure 4 shows production, inventory levels and lost demand in a situation without flexibility and without overtime. Figure 5 shows the same information; one can see how inventory levels and lost demand can be diminished due to the flexibility provided by annualised hours, even when reducing annual working time. 


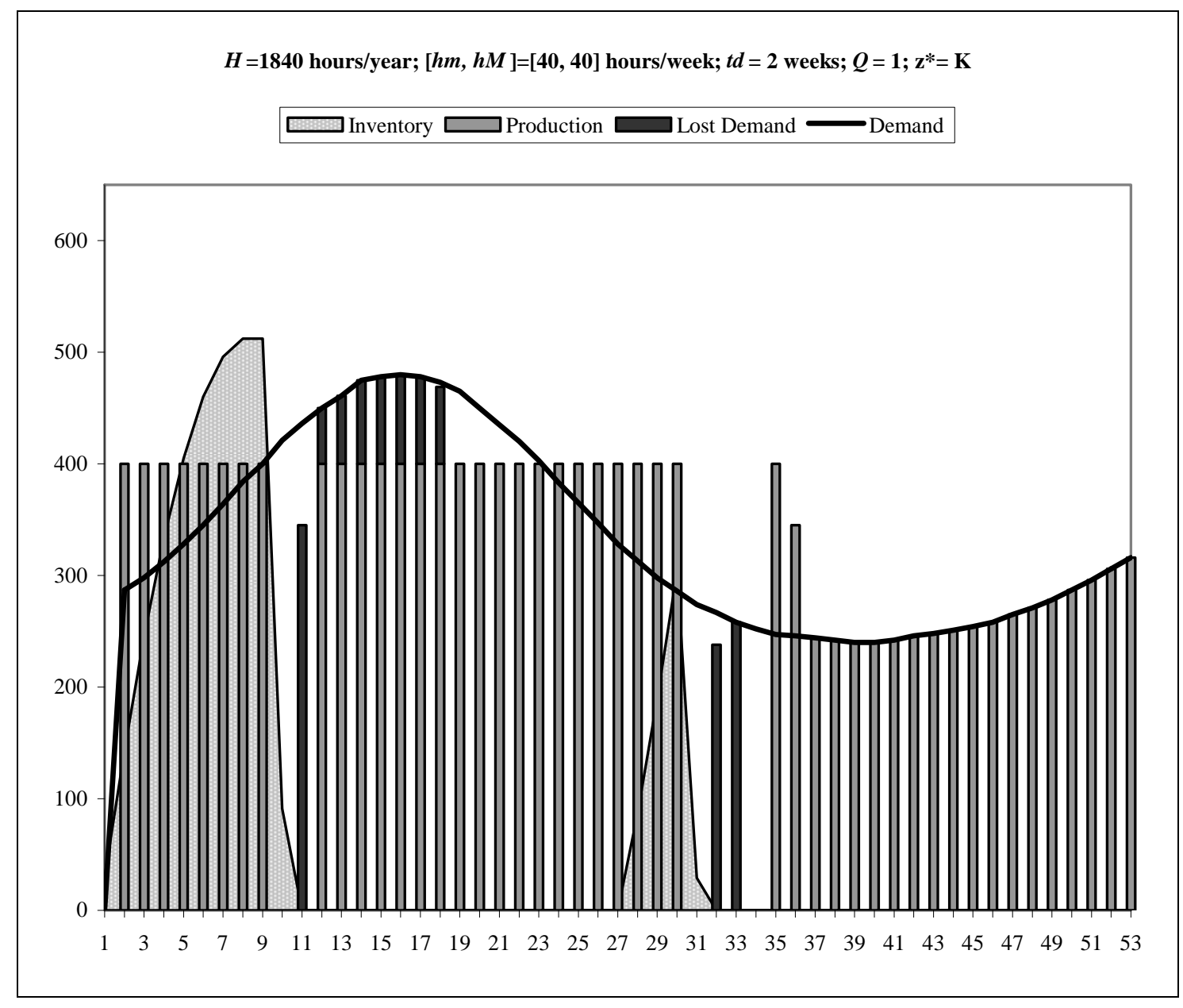

Figure 4. Production, lost demand and inventory $(H=1840$ hours/year; [hm, $h M]=[40,40]$ hours/week; td $=2$ weeks; $\left.Q=1 ; \mathrm{z}^{*}=\mathrm{K}\right)$ 


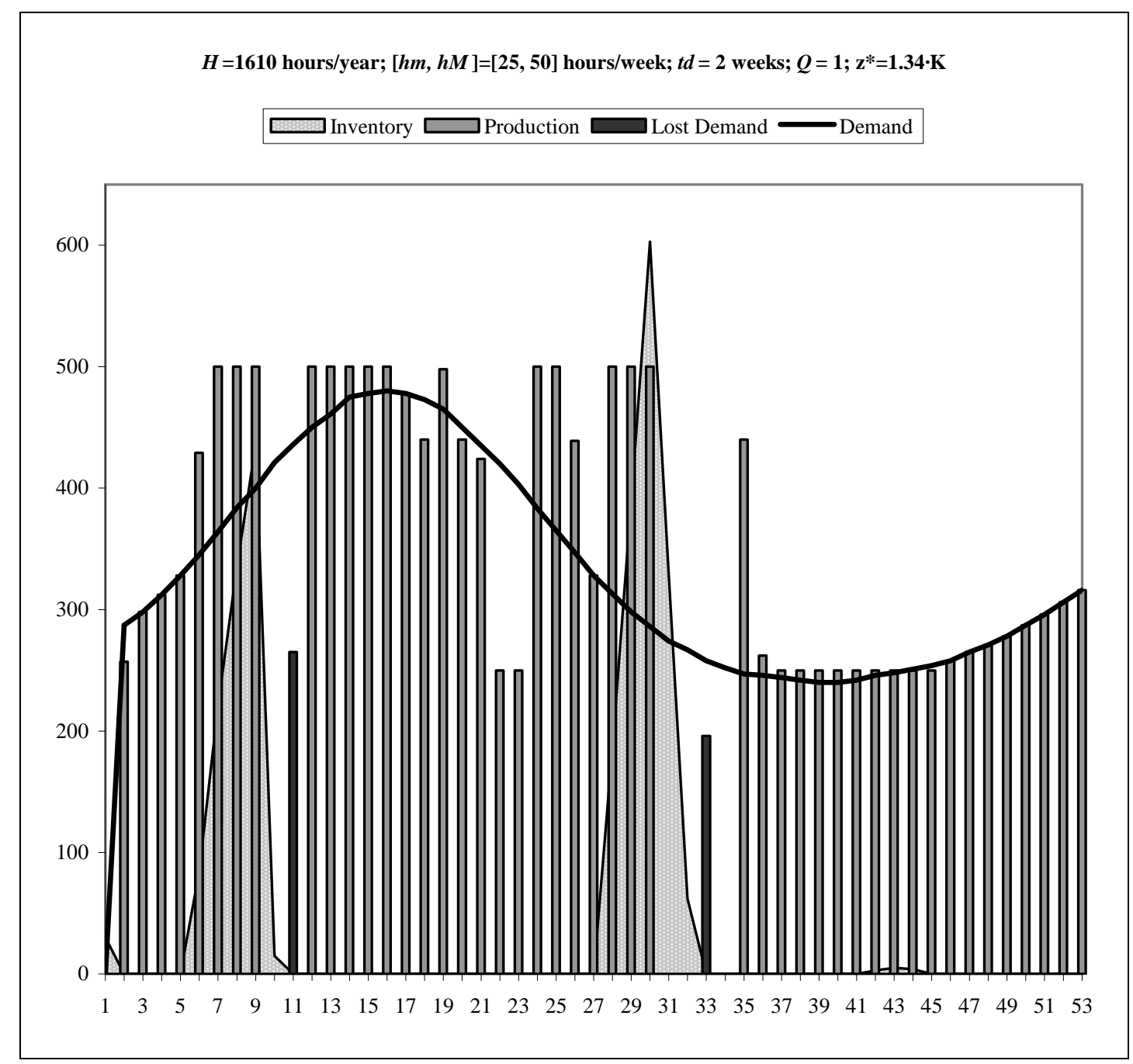

Figure 5. Production, lost demand and inventory $(H=1610$ hours/year; [hm, $h M]=[25,50]$ hours/week; $t d=2$ weeks; $\left.Q=1 ; \mathrm{z}^{*}=1.34 \cdot \mathrm{K}\right)$

By analysing the results obtained (for $Q=1$ product), one can see that, with the specific parameters used in the computational experiment, an increase in flexibility -without a reduction in working time- produces, on average, a decrease of $45 \%$ in the inventory level and a $100 \%$ reduction in lost demand.

\section{Conclusions and further research}

Annualising working hours is a good and economical way of adjusting productive capacity to seasonal demand and to obtain flexibility in the distribution of annual working hours. Annualising 
entails new problems to be faced, particularly those associated with planning both production and the weekly number of working hours on an annual scale while respecting the constraints established by law and those forged in collective bargaining agreements in order to take into account workers' working conditions. This paper presents a specific problem of planning working hours and production in industries. It also presents an optimisation model for solving the problem. A computational experiment showed that MILP is an efficient tool for solving the problem in an optimal way.

Furthermore, considering different levels for annual working hours (with or without working time reduction) and different levels for weekly flexibility when solving the problem provides the company and the workers with adequate information to negotiate the conditions of an annualised hours system. The company will then see how profit increases when flexibility is high, even when reducing working time or offering financial compensation to the workers for the worsening of their working conditions.

The company could gain a more precise idea of profit by considering the financial costs associated with the planning (e.g., if a lot of overtime is needed during a given period, the firm would perhaps have to ask for a bank loan to finance it). These costs have been traditionally ignored in planning models, and our future research will try to introduce them in annualised-hours planning models.

Finally, we will continue to solve other problems based on the classification scheme proposed in Corominas et al. (2002a); for example, products can be perishable and this feature may add a great number of variables and constraints to the model, making it more difficult to solve.

\section{References}

C. Azmat; M. Widmer. (2004). A case study of single shift planning and scheduling under annualized hours: A simple three step approach. European Journal of Operational Research, 153, $1,148-175$

G. M. Campbell; M. Diaby. (2002). Development and evaluation of an assignment heuristic for allocation cross-trained workers. European Journal of Operational Research, 138, 9-20. 
P. Chan; G. Weil. (2002). Using Multiple-level Models to solve large-scale employee scheduling. Paper presented at European Conference for Artificial Intelligence 2002; July 21-26 2002, Lyon, France.

D. Clutterbuck. (1982). After flexible hours, now it’s flexiyears. International Management, 37 (3), 31-36.

A. Corominas; R. Pastor. (2000). Manpower planning and scheduling in services with seasonal demand. Proceedings of the I World Conference on Production and Operations Management. Machuca, J.A.D. and Mandakovic, T., eds.; August 27-September 1, 2000, Sevilla, Spain.

A. Corominas; A. Lusa; R. Pastor. (2002a). Characteristics and classification of the annualised working hours planning problems. Working Paper, IOC-DT-P-2002-18, UPC, Barcelona (to be published in the special issue "Lean Services Management" of the International Journal of Services Technology and Management).

A. Corominas; A. Lusa; R. Pastor. (2002b). Using MILP to plan annualised hours. Journal of the Operational Research Society, 53 (10), 1101-1108.

A. Corominas; A. Lusa; R. Pastor; A. Sanchez. (2002c). Planning annualised hours with a finite set of weekly working hours and cross-trained workers. Working Paper, IOC-DT-P-2002-22, UPC, Barcelona.

A. Corominas; A. Lusa; R. Pastor. (2004). Planning annualised hours with a finite set of weekly working hours and joint holidays. Annals of Operations Research, 128, 217-233.

P. Curran. (1992). Annual hours brings productivity boost to Spicers. Management Services, July, 32-33.

B. Grabot; A. Letouzey. (2000). Short-term manpower management in manufacturing systems: new requirements and DSS prototyping. Computer Industries, 3 (1), 11-29.

A. Hax; H. Meal. (1973). Hierarchical integration of production planning and scheduling. Working Paper, Sloan School of Management, MIT.

A. Hax; D. Candea. (1984). Production and Inventory Management. Prentice-Hall.

C. C. Holt; F. Modigliani; J. M. Muth; H. A. Simon. (1960). Planning, Production, Inventories and Work Force. Prentice-Hall.

R. Hung. (1997). Annualized hours and aggregate planning. Production and Inventory Management, 38 (4), 48-50.

R. Hung. (1999a). A multiple-shift workforce scheduling model under annualized hours. Naval Research Logistic, 46 (6), 726-736. 
R. Hung. (1999b). Scheduling a workforce under annualized hours. International Journal of Production Research, 37 (11), 2419-2427.

L. A. Johnson; D. C. Montgomery. (1974). Operations Research in Production Planning, Scheduling and Inventory Control. John Wiley and Sons.

P. Lynch. (1995). Annual Hours: An idea whose time has come. Personnel Management, November, 46-50.

J. MacMeeking. (1995). Why Tesco's new composite distribution needed annual hours. International Journal Retail Distribution Management, 23 (9), 36-38.

L. Mazur. (1995). Coming: the annual workweeks. Across the Board, 32 (4), 42-45.

MES: Ministére de l'Emploi et de la Solidarité (2003): www.35h.travail.gouv.fr. 04/28/2003. France.

A. Oke. (2000). Linking human resource flexibility with manufacturing flexibility: enablers of labour capacity flexibility in manufacturing plants. Proceedings of the I World Conference on Production and Operations Management. Machuca, J.A.D. and Mandakovic, T., eds.; August 27September 1, 2000, Sevilla, Spain.

G. F. E. Vila; J. M. Astorino. (2001). Annualized hours as a capacity planning tool in make-toorder or assemble-to-order environment: an agricultural implements company case. Production Planning \& Control, 12, 4, 388-398. 